\title{
A MODERNIDADE NAS TEIAS DA FLORESTA: O BRASIL NA EXPOSIÇÃO UNIVERSAL DA FILADÉLFIA DE 1876
}

\author{
Marina Monteiro Machado ${ }^{1}$ \\ Mônica de Souza Nunes Martins ${ }^{2}$
}

\begin{abstract}
Resumo: O presente artigo realiza uma breve discussão sobre os aspectos que envolvem a concepção de modernidade inserida na participação do Brasil nas Exposições Universais da segunda metade do século XIX, especialmente a partir do exemplo da Exposição da Filadélfia, em 1876, problematizando o contraponto geralmente abordado entre desenvolvimento tecnológico e exibição de recursos naturais pela historiografia. Pretende-se mostrar como o Brasil se inseriu nesses grandes eventos internacionais a partir da divulgação das suas riquezas naturais, como parte da construção de uma dada noção de modernidade que atendia aos interesses de vários setores proprietários no país.
\end{abstract}

Palavras-chave: Exposições Universais; Modernização; Riquezas Naturais

\section{THE MODERNITY IN THE FOREST WEBS:}

\section{BRAZIL AT THE UNIVERSAL EXPOSITION OF PHILADELPHIA OF 1876}

\begin{abstract}
This article presents a brief discussion about the aspects that involve the conception of modernity inserted in the participation of Brazil in the Universal Expositions of the second half of the 19th century. Especially from the example of the Philadelphia Exposition in 1876, problematizing the counterpoint usually addressed between Technological development and exhibition of natural resources by historiography. It intends to show how Brazil was inserted in these great international events from the divulgation of its natural wealth, as part of the construction of a certain notion of modernity that served the interests of several proprietary sectors in the country.
\end{abstract}

Keywords: Universal Expositions; Modernization; Natural Resources

\section{A MODERNIDADE EN LAS MONTAÑAS: O BRASIL EN LA EXPOSICIÓN UNIVERSAL DA FILADÉLFIA DE 1876}

Resumen: El presente artículo realiza una breve discusión sobre los aspectos que involucran la concepción de modernidad insertada en la participación de Brasil en las Exposiciones Universales de la segunda mitad del siglo XIX. Especialmente a partir del ejemplo de la exposición de Filadelfia, en 1876, problematizando el contrapunto generalmente abordado entre Desarrollo tecnológico y exhibición de recursos naturales por la historiografía. Se pretende

\footnotetext{
${ }^{1}$ Marina Monteiro Machado é professora de História Econômica da Faculdade de Ciências Econômicas da UERJ e do Programa de Pós-Graduação em História da UERJ (PPGH-UERJ). Email: marinamachado@ gmail.com

${ }^{2}$ Mônica de Souza Nunes Martins é professora de História Econômica e Teoria da História do Departamento de História da UFRRJ, do Programa de Pós-Graduação em História da UFRRJ (PPHR) e do Programa de PósGraduação Patrimônio, Cultura e Sociedade da UFRRJ (PPGPACS). As autoras são membros do INCT Proprietas e coordenam o Núcleo de Pesquisa da Propriedade e suas múltiplas dimensões (NUPEP), apoiado pela FAPERJ. Email: monic1922@gmail.com
} 
mostrar cómo Brasil se insertó en esos grandes eventos internacionales a partir de la divulgación de sus riquezas naturales, como parte de la construcción de una dada noción de modernidad que atendía a los intereses de varios sectores propietarios en el país.

Palabras clave: Exposiciones Universales; Modernización; Riquezas Naturales

\section{Notas introdutórias}

O impacto das Exposições Universais no mundo na segunda metade do século XIX foi estrondoso, e espelhou o deslumbramento global com a rapidez das invenções e das mudanças tecnológicas e industriais, projetando também os desejos de consumo individuais e coletivos. Apresentava-se nessas feiras uma perspectiva da modernidade que buscava a valorização do engrandecimento das nações industrializadas, que se exibiam ao resto do mundo, em grande parte constituído de regiões colonizadas ou dependentes das primeiras. Canais de difusão de informação, conhecimento e invenções, as Exposições também se tornaram espaços da diferença, uma grande vitrine formada pela composição entre os valores de civilização e progresso, que marcavam política e ideologicamente o avanço das perspectivas imperialistas consolidadas naquele momento.

No século XIX, a economia capitalista apresentou significativas mudanças que impactaram as relações entre as nações, transformando decisivamente o lugar de cada uma delas nessa nova divisão internacional do trabalho, alicerçando as bases imperialistas da economia mundial. Para Hobsbawm, ${ }^{3}$ quatro elementos foram decisivos nessa consolidação do imperialismo no final dos oitocentos: a entrada em uma nova era tecnológica; o aprofundamento de uma economia de mercado de consumo de massa; a competição internacional entre economias industriais rivais; a concentração econômica, o controle de mercado e a manipulação. Essas foram as bases de uma nova organização econômica que subordinava os países "subdesenvolvidos" às potências industrializadas rivais. Nesse ponto, é importante destacar que as economias agroexportadoras ocupavam papel fundamental nessa ordem, sustentando o desenvolvimento científico e tecnológico a partir do fornecimento de matérias primas, centradas na riqueza natural que possuíam e que nesse momento tornava-se, mais que nunca, fonte de cobiça para o processo de industrialização.

É a partir desse contexto que as Exposições Universais, iniciadas em Londres em 1851, devem ser lidas. Foram marcadas ao longo do século XIX como espetáculos antropológicos por

${ }^{3}$ HOBSBAWM, Eric. A Era do Capital. 1848-1875. 9a ed. Rio de Janeiro: Paz e Terra, 1996. 
exibir a face "exótica" do mundo não europeu: tribos diversas, indígenas, negros escravizados e tantos outros eram apresentados em espetáculos mórbidos onde se dava ênfase às diferenças entre os povos "civilizados" e os "bárbaros". As feiras internacionais não deixavam de projetar valores fundamentais para ratificar a dominação imperialista no mundo e produzir as necessárias diferenciações de valores ideológicos que a sustentavam. ${ }^{4}$

Inicialmente projetadas para a divulgação de produtos e invenções, essas feiras se transformaram ao longo de suas várias edições. Tornaram-se reconhecidas também como ambientes de exibição das melhorias relacionadas ao universo de trabalhadores da indústria ou dos mecanismos excepcionais para a adequação da disciplina destes, das condições de vida e trabalho dos operários. Os eventos tinham uma perspectiva educadora e civilizadora, típica da conjuntura oitocentista. ${ }^{5}$ Aos poucos, artigos relacionados à vida dos trabalhadores ganharam espaço nas exibições, o que é bastante significativo, pois levavam as vitrines do progresso burguês a se renderem a uma relativa popularização. Era o sinal de que as Exposições não geraram impacto apenas no modo de vida das classes médias, mas também agiram no âmbito simbólico e econômico na vida dos trabalhadores, na medida em que exibiam o que se tornaria desejo de consumo, por responderem às necessidades imediatas ou por popularizarem o acesso a artigos frívolos e até luxuosos. Era a primeira vez na história que significativas parcelas das sociedades, de todos os continentes, passavam a ter algum acesso, via econômica ou pela projeção de desejos, a objetos que não faziam parte do âmbito das necessidades fundamentais, mas figuravam como supérfluos.

\section{O Brasil exposto ao mundo: o que exibir?}

Segundo uma historiografia clássica sobre o tema, as Exposições Universais passaram a ser conhecidas como grandes vitrines de modernidade que exibiam a consolidação do sistema fabril ao grande público e para as demais nações. Era como se os mais recentes inventos e as tecnologias, até então confinados ao interior das fábricas, rompessem esses limites para serem

\footnotetext{
${ }^{4}$ Robert W. Rydell em All the world's a fair: visions of Empire at American International Expositions, 1876-1916 (Chicago: University of Chicago Press, 1984), descreve as exibições internacionais como "parques temáticos do imperialismo", onde os estandes antropológicos mostravam povos colonizados, contrapondo o mundo primitivo ao avanço tecnológico dos povos do Atlântico Norte.

${ }^{5}$ KUHLMANN Jr., Moysés. "As Exposições universais e a utopia do controle social”. XVII Simpósio Nacional de História. Anais do XVII Simpósio Nacional de História. São Paulo, julho 1993. pp.169-170.
} 
vistos e ostentados como símbolo de um capitalismo triunfante, reverberando também os hábitos, costumes e consumo da sociedade burguesa. Tiveram o potencial de impactar as relações comerciais do mercado mundial, tornando-se um amplo painel do que era produzido em colônias, estados e nações pelo mundo afora, e do progresso viável vivenciado por determinadas classes nos países industrializados. ${ }^{6}$

O Brasil esteve no cerne destas Exposições e inserido de forma bastante peculiar: uma nação que ao longo de todo o século XIX manteve as estruturas de produção predominantemente agrícolas e escravistas, o "Império dos Trópicos" era ainda internacionalmente reconhecido pelo tradicionalismo e exotismo dos produtos indígenas no meado dos oitocentos. Destacamos que o império participou de todas as feiras a partir da terceira edição, que aconteceu na cidade de Londres, em 1862. Como grande incentivador e porta-voz dessa edição esteve o próprio imperador, Dom Pedro II, que não mediu esforços para passar ao mundo uma imagem civilizada e moderna do Brasil, procurando distinguir-se frente às demais nações republicanas da América Latina. O monarca, conforme destaca Lilia Schwarcz, tomou lugar com presença ativa em todo o processo que culminava na participação brasileira nestes eventos internacionais, atuando em seleções de pedidos de patente e privilégios industriais, bem como foi, ele próprio e sua família, presenças marcantes nas mostras nacionais. ${ }^{7}$ Tal regularidade e cuidado com a participação do Brasil não era sem propósito, revelava o empenho do imperador e dos grupos que o cercavam na corte em consolidar uma imagem que se distanciasse da tradição agrícola, monárquica e escravocrata, passando a ideia de uma nação moderna e cosmopolita. $\mathrm{O}$ investimento não visava apenas ao retorno financeiro imediato, com a inserção de produtos brasileiros no mercado exterior, mas mirava mais adiante, mantendo o foco na propaganda e na visibilidade que se desdobravam a partir da participação nas feiras.

Ainda que procurando explorar sua faceta mais moderna e inserindo-se no ambiente de invenções industriais, ao apresentar-se nas Exposições, o Império do Brasil era rotineiramente lembrado pelas florestas, produtos agrícolas e indígenas. Isso parece ter de fato feito parte de uma

\footnotetext{
${ }^{6}$ PESAVENTO, Sandra Jatahy. Exposições universais: espetáculos da modernidade no século XIX. São Paulo: Editora Hucitec, 1997. PLUM, Werner. Exposições no século XIX: espetáculos da transformação sócio-cultural. Bonn: Friedrich-Ebert-Stiftung, 1979. BARBUY, Heloísa. "O Brasil vai a Paris em 1889: um lugar na Exposição Universal”. Anais do Museu Paulista. São Paulo, v.4, pp. 211-240, dez. 1996.

${ }^{7}$ SCHWARCZ, Lilia Moritz. "Exposições Universais: festas do trabalho, festas do progresso". In: As barbas do imperador: D. Pedro II - um monarca nos trópicos. São Paulo: Cia das Letras, 1998. pp. 385-407.
} 
proposital estratégia de exibição do Brasil ao mundo. ${ }^{8}$ Buscando o reconhecimento a partir de suas riquezas naturais, que de certo despertavam a curiosidade de muitos dos visitantes, em sua primeira participação o Brasil foi representado por suas preciosidades: café, chá, erva-mate, guaraná, arroz, borracha, tabaco, madeira, fibras vegetais, abelhas, algodão e ferro. Completando a lista com os produtos industriais apresentou maquinaria em geral, materiais de estradas de ferro, construção civil, telégrafo e armamentos militares. Para autores como Schwarcz, esses últimos, por sua vez, não despertaram a atenção esperada. ${ }^{9} \mathrm{O}$ que nos leva a questionar qual seria exatamente a expectativa brasileira ao exibir-se para o mundo uma vez que não se apresentava como nação industrializada e seu potencial se restringia principalmente à produção agrícola e exibição de produtos da flora e fauna brasileira.

É necessário pontuar o impacto que esses eventos geraram na economia brasileira e como o Brasil se inseriu de forma periférica no mercado internacional de bens tecnologicamente complexos. Preocupados com as invenções e as garantias estatais para sua proteção e difusão, todos os países foram impactados pela necessidade de implementar políticas mais rigorosas nesse sentido. Disso apreende-se toda a preocupação consolidada na esfera jurídica em diversos países a respeito da propriedade intelectual no final do século XIX com o intuito de proteger e restringir o uso e divulgação das invenções, ainda que sob a bandeira ideológica do liberalismo econômico. ${ }^{10}$ Tratava-se de garantir privilégios exclusivos que marcassem, sobretudo, as invenções realizadas em determinados locais do mundo, garantindo a eles a diferenciação no mercado mundial. Mas estabelecia, também, as balizas que separavam aqueles que seriam reconhecidos como "vocacionados" para a produção agrícola e os países que tinham as condições de impulsionar o desenvolvimento industrial.

Aqui pretendemos analisar as Exposições Universais a partir do recorte específico da participação brasileira, o que circunscreve o significado dos limites de sua participação nesses eventos como exibidor de matérias primas e dos seus recursos naturais. Cabe-nos refletir sobre

\footnotetext{
${ }^{8}$ CRIBELLI, Teresa. "Forests at the fair: Natural resources narratives of progress in the Brazilian and U. S. exhibits at the 1876 Philadelphia Exhibition". In: XXX International Congress of the Latin American Studies Association, San Francisco, maio 2012. MARTINS, M. "O impacto das Exposições Universais do século XIX para as relações econômicas brasileiras e o avanço tecnológico: uma análise sobre a participação das províncias". In: XII Congresso Brasileiro de História Econômica e 13 $^{\text {a }}$ Conferência Internacional de História de empresas. Niterói:UFF/ABPHE, 2017.

${ }^{9}$ Os dados acerca dos produtos exibidos nas feiras foram apresentados por SCHWARCZ, op. cit.

${ }^{10}$ No ano de 1883 reuniu-se a Convenção da União de Paris (CUP) agregando nações em torno da construção e aprovação do Primeiro Tratado Internacional da Propriedade Industrial. Sobre o tema ver: MALAVOTA, L. M. A construção do sistema de patentes no Brasil: um olhar histórico. Rio de Janeiro: Editora Lumen Juris, 2011.
} 
como o Brasil apresentava uma imagem de modernidade nos trópicos, ao mesmo tempo em que buscava consagrar-se com os elementos que o atrelavam ao atraso, associados a uma agricultura com utilização de pouco recurso técnico, utilização da mão de obra escrava e um frágil parque fabril, com baixo investimento em tecnologia. Não se trata, portanto, de um antagonismo entre invenções/tecnologia versus recursos naturais, mas pensá-los dentro de um mesmo plano de análise ligado a diferentes projetos de modernidade que cabiam a cada uma das nações no capitalismo internacional naquele momento.

\section{Modernidade ou Atraso: algumas reflexões}

Existe uma concepção bastante comum acerca da existência de uma dicotomia que colocava a presença um tanto "deslocada" do Brasil no seio das Exposições Universais. A frágil estrutura fabril acabava por fazer frente ao predomínio da demonstração de seu universo agrícola e suas riquezas naturais, o que para muitos terminava por se revelar um contrassenso nos eventos que cultuavam a tecnologia. Faz-se necessário, no entanto, ajustarmos o nosso foco de análise, pontuando o real sentido no qual a modernidade brasileira se inseria com um projeto específico de economia, de base escravista, centrada no cultivo e extração de matérias primas para exportação. É desse lugar que o Brasil moderno, que era enviado ao exterior, precisa ser visto e reconhecido em uma análise do século XIX: apresentando ao mundo com o que tinha de melhor, usufruindo ainda do benefício de gerar capital a partir do que selecionava exibir.

Eram muitas as preocupações com a proteção sobre as invenções, que podem ser analisadas também à luz das inovações almejadas pela indústria e pelo novo ambiente simpático ao empenho tecnológico, ao aperfeiçoamento das técnicas e ao investimento nesses avanços, que gerou acaloradas discussões também no Brasil. Estamos diante de uma conjuntura global, entre o final do século XIX e início do XX, na qual as ideias de avanço tecnológico, modernização e industrialização atrelavam-se à discussão corrente sobre desenvolvimento econômico dos países. O processo industrial, iniciado com o carvão e o vapor no século anterior e reflexo de transformações tecnológicas e sociais fomentadas pelo advento da segunda etapa da industrialização em curso na Europa e nos Estados Unidos, era apresentado à metalurgia, à criação da siderurgia, à consolidação do uso da eletricidade e do petróleo. Uma profunda 
transformação técnica na produção e criação de novos produtos e materiais, centrados por sua vez na vasta expansão da produção científica e do aprimoramento técnico.

Investimentos e financiamentos chegavam por empresas privadas e pelos governos na forma de pesquisas científicas de ponta. Objetivava-se a dianteira na crescente competição capitalista nesse cenário internacional. O perfil apresentado pelo Brasil, entretanto, é bem diverso, indicando a convivência entre dois aspectos distintos: por um lado, a intenção e o comprometimento de alguns setores da sociedade com um processo de modernização; por outro, a intencional exibição de um tradicionalismo que despertava a atenção daqueles que visitavam os estandes brasileiros nas feiras internacionais. O que poderia ser enquadrado como arcaico, portanto, também atuava como estratégia de divulgação da diferença, valorizando-se pontualmente aquilo que poderia angariar consumidores.

Nesse ponto, ao tratar sobre o próprio desenvolvimento industrial e técnico no Brasil, pensamos não ser em si a escravidão o ponto mais forte de resistência a ele, mas a compreensão de que determinada organização econômica e do trabalho se adequava melhor aos interesses econômicos e políticos dos proprietários naquele momento, ainda que sob uma lógica escravista. Sem dúvida, isso foi um aspecto importante no embate de ideias entre proprietários das mais variadas estirpes no final do século XIX. ${ }^{11}$

No Brasil, alguns setores ligados aos empresários e aos proprietários expressaram preocupação de que a Exposição revelasse ao mundo aspectos conexos ao atraso da agricultura, à falta de investimentos efetivos na industrialização e, especialmente, à escravidão, questionada internacionalmente, sobretudo pela Inglaterra. A apreensão foi esboçada pelos membros da Sociedade Auxiliadora da Indústria Nacional (SAIN) ${ }^{12}$ em seus relatórios das Exposições, nos

\footnotetext{
${ }^{11}$ A bibliografia que tratou das contradições entre o liberalismo e escravidão ou da conformação entre ambas é farta e já clássica. Atemo-nos a indicar aqui a leitura do artigo de Rafael Marquese, onde o autor trata de um liberalismo escravista atlântico, apontando que tanto nos Estados Unidos como no Brasil houve uma adequação de todo o sistema jurídico para legitimar a irrestrita soberania doméstica dos senhores sobre os escravos. Exemplo significativo disso foi o insucesso das propostas formuladas por José Bonifácio no Brasil, em 1823, que previam uma ação do Estado sobre a soberania doméstica dando limites à exploração do trabalho escravo, aos castigos físicos e propondo uma série de iniciativas que findariam gradualmente com a escravidão criando condições para que eles tivessem após as alforrias condições de sustento. Ver: MARQUESE, Rafael. "Governo dos escravos e ordem nacional: Brasil e Estados Unidos, 1820-1860”. Penélope, n. 27, pp.59-73, 2002.

${ }^{12}$ Entidade fundada em 19 de outubro de 1827, na cidade do Rio de Janeiro, então capital do Império. Em 1904, fundiu-se com o Centro Industrial de Fiação e Tecelagem de Algodão, dando origem ao Centro Industrial do Brasil (CIB). Idealizada por Inácio Álvares Pinto de Almeida, e tendo como primeiro presidente João Inácio da Cunha, o visconde de Alcântara, a sociedade propunha, de acordo com seus estatutos, "promover, por todos os meios ao seu alcance, o melhoramento e a prosperidade da indústria no Império do Brasil".
} 
quais mantiveram postura crítica à participação do Brasil, ainda que o Imperador determinasse a inserção das províncias na realização das exposições nacionais, garantindo um processo de seleção dos artigos que seriam levados ao público internacional. ${ }^{13} \mathrm{O}$ desassossego não era sem propósito: as exposições internacionais apresentavam ao mundo as novas invenções nos ramos do conhecimento como engenharia, química, siderurgia, entre outros. No Brasil, como explicitado, ainda ressoava a ideia do retardo industrial, e o temor em demonstrar sua realidade escravista, o constrangimento em ver a imagem distorcida frente às nações industrializadas parece ter sido um ponto importante a se levar em conta. ${ }^{14}$

Sem dúvida a presença brasileira nas Exposições contribuía para impulsionar o Império para o seio dos debates sobre a modernidade, legitimando a produção de uma narrativa sobre o progresso da qual o país se tornava partícipe. Nesse sentido, salientamos duas propostas à reflexão fundamentais: o debate que abrange a concepção sobre a modernidade, então aplicada a uma urgência sobre avanço tecnológico no Brasil; e a apresentação de aspectos aparentemente contraditórios - a exibição de um enorme país com dimensões continentais, e a ênfase em seu atraso e exotismo. Esse último ponto levantado evidencia um aspecto peculiar e dialoga fortemente com o lugar de modernidade que o país pretendia ocupar no cenário internacional.

Não entraremos no debate cultural sobre a modernidade, mas no sentido do impacto que essa noção exerceu para a vida econômica nacional naquele momento. Nesse aspecto, nos baseamos na análise desenvolvida por Teresa Cribelli, que se debruça sobre um curioso episódio, envolvendo as tentativas de introdução do arado no Brasil. O arado foi considerado nos oitocentos um símbolo importante do avanço técnico na lavoura, tanto para o processo de renovação da terra e melhoria de sua qualidade para novas culturas, como para a quantidade da produção. Embora aparentemente simples, moderna e vantajosa, a chegada do novo instrumento não foi tão bem recebida quanto esperado, confrontando-se com uma série de questões como a dificuldade com seu transporte, a falta de conhecimento técnico para seu uso e sua adequação à realidade do solo das regiões do Brasil, bem como a resistência a um novo instrumento, visto

\footnotetext{
${ }^{13}$ MARTINS, Mônica. "O impacto das Exposições Universais do século XIX para as relações econômicas brasileiras e o avanço tecnológico: uma análise sobre a participação das províncias". Anais do XII Congresso Brasileiro de História Econômica e 13 ${ }^{\text {a }}$ Conferência Internacional de História de Empresas. Niterói: UFF/ABPHE, 2017.

${ }^{14}$ FERREIRA, Cristina Araripe. Difusão do conhecimento científico e tecnológico no Brasil na segunda metade do século XIX: a circulação do progresso nas exposições universais e Internacionais. 2011. 138 f. Tese de Doutorado em História das Ciências e da Saúde, Fundação Oswaldo Cruz, Rio de Janeiro.
} 
com desconfiança pelos agricultores. A partir deste exemplo, Cribelli analisa o lento processo de modernização, característico do modelo de desenvolvimento brasileiro. ${ }^{15}$

Partindo de uma questão aparentemente simples - a utilização do arado, um dos símbolos de modernidade no século XIX - e a garantia no melhoramento das terras, com consequente aumento da produtividade, a autora adentra um terreno muito mais complexo, demonstrando que o valor monetário das terras era apenas parte do problema a ser observado. Isso porque na dualidade entre o arar ou não arar, pairava a forte ideia, consagrada por muitos autores, de que a manutenção das divisas escravocratas eram responsáveis pela escassez de incentivos técnicos no campo, atrasando o processo de modernização da agricultura. Soma-se ainda a ideia de que a escravidão em si não contribuía, e até mesmo atravancava os incentivos aos processos de criação, invenção ou novas descobertas.

É possível afirmar que tal ponto de vista é corroborado por uma forte perspectiva do pensamento liberal do século XIX, propagador dessa premissa, inclusive como argumento de contestação econômica à manutenção do trabalho escravo. ${ }^{16} \mathrm{~A}$ autora, no entanto, em vez de seguir o já tradicional debate sobre a manutenção das relações escravistas e o atraso da agricultura, vai além ao analisar um conjunto muito mais complexo de relações sociais que dificultaram a implementação de uma técnica mais moderna para o trato agrícola. Cribelli recupera estudos que saíram em defesa da melhoria nas técnicas para recuperação das condições do solo para a promoção da agricultura, possibilitando melhores resultados nas colheitas a longo prazo, bem como melhores valores mercadológicos para a própria propriedade da terra. Para tanto, destaca dois fatores que merecem ser pontuados na diferenciação da incorporação do uso do arado no Brasil em comparação com a Europa e os Estados Unidos. O primeiro seria o fato de que, apesar da tecnologia apresentar bons resultados na Europa, essa não seria uma realidade assegurada no Brasil dadas as especificidades da geografia, de característica irregular e montanhosa. Em segundo lugar, a autora atenta para as dificuldades de transporte e o alto

\footnotetext{
${ }^{15}$ CRIBELLI, Teresa. "O mais útil de todos os instrumentos: o arado e a valorização da terra no Brasil no século XIX”, In: MOTTA, Márcia e SECRETO, Verônica (Orgs.). O Direito às avessas: por uma História Social da Propriedade. Guarapuava: Unicentro, 2011; Niterói: Eduff, 2011, pp. 291-312; CRIBELLI, Teresa. Aperfeiçoar or Criar: dilemmas of Brazilian modernization, 1850-1889. 2009. Tese (Doutorado em Filosofia), The Johns Hopkins University, Baltimore, Maryland.

${ }^{16}$ Sobre o debate destacamos dois autores em especial, que, em conjunturas distintas do século XIX, saíram em defesa da abolição da escravatura em prol da modernização das técnicas agrícolas. SILVA, José Bonifácio de Andrada e. "Representação à assembleia geral constituinte e legislativa do Império do Brasil sobre a escravatura" In: DOLHINIKOFF, Miriam. José Bonifácio de Andrada e Silva: Projetos para o Brasil. São Paulo: Companhia das Letras, 1998. NABUCO, Joaquim. O Abolicionismo. São Paulo: Publifolha, 2000.
} 
dispêndio financeiro, que inviabilizavam o translado de equipamentos de grande porte, em especial para fazendas mais distantes da Corte ou dos portos.

Os empecilhos para o avanço agrícola iam além dos obstáculos físicos dos campos irregulares e das dificuldades de transporte, incluindo outros problemas como a falta de infraestrutura para a manutenção e reparo de equipamentos, especialmente dos importados de países diferentes. Muitas fazendas grandes eram empresas autossuficientes, completas com fundição e carpintarias, mas isso não era possível para lavradores menos abastados, que não dispunham dos recursos para sustentar operações tão caras, e ficavam sem auxílio quanto à recomendações ou reparos para seus equipamentos. Rocha Pacova, assim como Marques Rodrigues e os membros da Sociedade Auxiliadora da Indústria Nacional, defendiam a criação de escolas agrícolas para fornecer esse tipo de apoio. $^{17}$

Além desses havia ainda aqueles empecilhos de ordem social ou cultural, resultado, por um lado, da relutância em se adaptar e incorporar novas técnicas que pudessem trazer melhorias na produção e no cultivo a longo prazo; por outro, do desconhecimento teórico necessário para entender as novas invenções e adaptá-las ao contexto agrícola brasileiro. $\mathrm{O}$ arado seria muito mais do que uma forma de modernizar o Brasil rural, não era apenas uma mera tecnologia, era um caminho que possibilitava transformações culturais, sociais e econômicas profundas, capaz de modificar a relação então estabelecida pelos agricultores com a própria terra. Os empecilhos enfrentados na adoção do arado, que deveria substituir a enxada usada essencialmente pelo trabalhador escravo, estavam ligados a uma mentalidade conservadora pautada, entre outros aspectos, na crença de uma extensão inesgotável de terras aráveis.

Ao se debruçar sobre a polêmica relação estabelecida diante das resistências na incorporação do arado como instrumento modernizador, Cribelli nos coloca diante de instigantes reflexões acerca do propósito assumido no processo de incorporação de invenções e tecnologias no Brasil no final do século XIX. O modelo que veio a ser implementado no Brasil foi resultado do longo debate sobre modernização: entre o industrializar ou não industrializar, ideias em confronto repercutiam de acordo com os interesses de cada um dos setores econômicos envolvidos. Tais elementos revelavam as ambições específicas e plurais na base das discussões realizadas pelas principais instituições e organizações da sociedade civil naquele momento. A disputa fundamental era sobre o Estado estar à frente de um planejamento industrial ou deixá-la

${ }^{17}$ Op. Cit. CRIBELLI (2011), pp. 306-307. 
sob a responsabilidade de agentes privados, o que significava a ausência de um comprometimento com a garantia de infraestrutura ampla, possibilitando o desenvolvimento fabril por todo o território nacional.

A disputa entre os diferentes projetos que estavam sendo levados adiante já foi objeto de estudos anteriores, ${ }^{18}$ e se tornou bastante evidente no seio da Sociedade Auxiliadora da Indústria Nacional, no que diz respeito aos estímulos à industrialização brasileira. Essas distensões são notáveis com relação aos debates sobre se o Brasil participaria da Exposição Universal de 1876, que ocorreu na Filadélfia, Estados Unidos, que rememorava os cem anos da independência deste país. Vale sublinhar que as datas e lugares sempre obedeceram a critérios políticos como pano de fundo, não sendo um mero acaso. O Brasil, convidado pelo governo americano a participar da citada Exposição, desencadeou intenso debate interno, não apenas sobre a presença na feira, apoiada diretamente por Dom Pedro II mas, sobretudo, acerca do que deveria ou não ser levado à exibição. ${ }^{19}$ Dava-se aí um embate sobre o que e como deveria ser mostrado, com que objetivos e atendendo a quais interesses.

Optou-se, no Brasil, por um modelo específico de seleção dos produtos a serem expostos. O primeiro passo era a formação da comissão organizadora da exposição nacional, todas realizadas na Corte, para onde eram enviados artigos diversos selecionados pelas províncias. A comissão organizadora cuidava de todo o processo que abrangia a distribuição dos recursos pelas províncias, estabelecimento dos critérios do que seria enviado, organização do catálogo da exposição e do que seria selecionado para ser exposto internacionalmente. A premiação servia de estímulo para esses eventos e para a participação de expositores diversos, que viam na Exposição a possibilidade de reconhecimento também de invenções e produções técnicas diversas. ${ }^{20}$

O grande destaque sobre a participação do Brasil na Exposição da Filadélfia volta-se sempre para a presença, em pessoa, do imperador. Ainda que procurasse apresentar-se com roupas civis, evitando as pompas e formalidades de um Imperador, sua presença, junto ao império tropical, foi uma das grandes atrações na Filadélfia. Sempre interessado e apreciador da

\footnotetext{
${ }^{18}$ MARTINS, Mônica. "A propriedade sobre o conhecimento: A participação do Brasil nas Exposições Universais do século XIX”, In: MOTTA, Márcia e PICCOLO (Orgs.). O domínio de Outrem: as propriedades na História (Brasil e Portugal, séculos XVIII e XX). Guimarães; São Luís: Editora Nós por cá tudo bem; EDUEMA, 2017.

${ }^{19}$ BARRETO, Rosendo Muniz. Exposição Nacional. Notas e observações. S/1, 1876, pp. 3-15.

${ }^{20}$ Sobre a realização de Exposições Nacionais na Corte com os produtos enviados pelas províncias, cf. MARTINS, Mônica. "O impacto das Exposições Universais do século XIX para as relações econômicas brasileiras e o avanço tecnológico: uma análise sobre a participação das províncias”. Anais do XII Congresso Brasileiro de História Econômica e 13 ${ }^{\text {a }}$ Conferência Internacional de História de Empresas. Niterói: UFF/ABPHE, 2017.
} 
tecnologia e da ciência, como bem destacou Lilia Schwarcz, Dom Pedro II presidiu a cerimônia de abertura da feira ao lado do presidente Ulysses Grant, juntamente com suas respectivas esposas, tendo a honra de puxar a alavanca que ligava a máquina a vapor Corliss, que ocupava três andares no Salão de Maquinarias, responsável por garantir a geração de energia para muitos outros equipamentos presentes durante toda a exposição.

Como em todas as exposições internacionais em que o Brasil esteve presente, foi elaborado um catálogo especialmente para a participação brasileira na Exposição da Filadélfia, que já em seu primeiro parágrafo, anunciava:

Se as Exposições Universais não podem, ainda, por parte do Brasil, servir para competência industrial, é inegável, que lhe tem proporcionado ensejo para ser melhor conhecido, e apreciado, como região agrícola de solo fertilíssimo, e nacionalidade pacífica; inteligente e laboriosa. ${ }^{21}$

Afirmação curta e direta, acompanhada por algumas características a serem destacadas. A franqueza e a segurança com que o Império se apresentava ao mundo, longe de cultivar a ideia do exótico, e/ou reduzir-se ao atraso, mostrava um reconhecimento dos seus limites no que tange a competência industrial, na mesma medida em que apresentava o desejo de ser reconhecido pela agricultura, fertilidade dos solos, inteligência e trabalho. Ao longo do referido catálogo, foram descritas minúcias revelando profundo conhecimento acerca das várias províncias, especificandose em todos os aspectos características do território, da população, da organização administrativa, além das associações científicas, dos transportes, das comunicações e, por fim, dos recursos naturais. E a esse ponto é onde o catálogo dedica seus maiores esforços, mostrando com detalhes os aspectos que envolvem os recursos naturais brasileiros em suas características e diversidade regionais, a que fins muitas vezes eles poderiam servir à indústria e produção de medicamentos e produtos em geral.

Mais adiante, citando como referência a obra de Von Martius, o texto afirma já serem conhecidas vinte mil diferentes espécies de plantas no Brasil, sendo “(...) inegável, que, relativamente a indústria; medicina; subsistência, e ornamento, ocupa um dos mais distintos lugares, senão o primeiro, no mundo". ${ }^{22}$ Seguindo com a descrição da madeira de construção, destaca o vasto uso para fins comerciais na engenharia, na marcenaria e na arquitetura de

${ }^{21}$ O Império do Brasil na Exposição Universal de 1876 na Philadelphia. Rio de Janeiro: Typographia Nacional, 1875.

${ }^{22}$ Idem, p. 49. 
construções civis e navais, para a qual havia uma ampla variedade. As plantas têxteis foram apresentadas cada uma de acordo com a função que poderiam desempenhar na indústria, reconhecendo-se suas características de resistência, qualidade do fio, dentre outras.

Ainda sobre a Exposição da Filadélfia, o pavilhão brasileiro foi detalhadamente descrito por Teresa Cribelli, pintado com tons vibrantes de castanho e azul, que contrastavam com a bandeira nacional verde e dourada, uma das estruturas mais notáveis e brilhantes do prédio principal. Segundo a autora, para muitos dos visitantes, o esplendor da estrutura superava os produtos apresentados, sendo a exaltação da presença do Imperador um dos grandes momentos da feira, ${ }^{23}$ o envolvimento pessoal do monarca na elaboração do estande brasileiro, participando diretamente das escolhas que envolveram a montagem e a seleção dos produtos. Os objetivos, não deixemos de pontuar, estavam diretamente voltados para a construção de uma determinada visão externa que se pretendia mostrar do Império brasileiro.

Essa iniciativa motivada pelos interesses econômicos alicerçava-se também nos ideais de modernidade difundidos naquele momento, envolvendo fatores simbólicos e ideológicos de forte apelo nacional. Uma opção que contribuía para forjar a ideia de uma sociedade que abraçava a cultura de vários povos, ao mesmo tempo em que se consagrava pela adesão a uma pretensa civilização, integrada aos ideais próprios ao discurso político de fins do XIX. Se o país não se inseria no epicentro, talvez um tanto estereotipado, do "mundo moderno e civilizado", parece claro, no entanto, que as Exposições para o Brasil promoveram a difusão e propaganda da produção agrícola para o mundo. Atendia, desta forma, às necessidades de crescente inserção nas redes de comércio internacionais, aspecto que vem sendo ratificado sobre outras províncias brasileiras por diversos estudos - tal como o de Sanjad e Castro ${ }^{24}$ - que demonstram os interesses em angariar atenção para produtos de potencial exibição internacional.

\section{A indústria e a floresta: o Brasil e suas matérias primas}

Grande parte dos estudos consagrados na historiografia que envolvem a participação brasileira nas Exposições Universais do século XIX consagrou a premissa de que por mais que o

${ }^{23}$ CRIBELLI, Teresa. "O Império das Palmeiras, os Estados Unidos descobrem o Brasil, 1789-1892". In: MARTINS, Ana Cecilia Impellizieri \& SOCHACZEWSKI, Monique (Orgs.) As Descobertas do Brasil: o olhar estrangeiro na construção da imagem do Brasil. Rio de Janeiro: Casa da Palavra, 2014. pp.70-127

${ }^{24}$ SANJAD, Nelson; CASTRO, Ana Raquel de Marques. Comércio, política e Ciência nas Exposições Internacionais. O Brasil em Turim, 1911. Revista Varia Historia, Belo Horizonte, v. 31, n. 57, pp. 819-861, set/dez 2015. 
país procurasse apresentar suas invenções, a fim de ser reconhecido pela modernidade, era famoso pela floresta, por seu exotismo e pela ampla exibição das matérias primas. Esses argumentos incorporavam em grande medida a própria visão de época, reafirmando de forma depreciativa a forma como o Brasil e outros países e regiões do mundo se inseriam e participavam desses eventos. Como já destacado, no entanto, o Império do Brasil esteve presente em todas as mostras a partir de sua terceira edição, dado que aponta para uma regularidade que não pode ser tomada como casual, nem tampouco como algo não intencional. Mais do que isso, consagrava-se como uma das grandes participantes das Exposições, com estandes que despertavam a procura e a curiosidade dos milhares de participantes a cada nova edição. Tamanha foi a importância que a cidade do Rio de Janeiro veio a ser palco de uma das Exposições Universais, já no século seguinte, quando em 1922 se celebravam os cem anos da Independência do Brasil.

Sobre este aspecto, voltamos mais uma vez para as reflexões da historiadora Teresa Cribelli que, em outro estudo, apresenta uma visão diferenciada a respeito dessa dualidade que envolve modernidade e tradição ou tecnologias industriais e agricultura. Segundo Cribelli, os recursos naturais assumiram importância igualmente diferenciada na construção das narrativas nacionais sobre o progresso, tal qual o discurso que associava o desenvolvimento tecnológico ao crescimento econômico. Isto posto, cumpre destacar que, de acordo com a autora, para o Brasil não se tratava apenas de exibir um exotismo, como tem sido pontuado pela historiografia, mas de observar que o Brasil possuía uma bem organizada e sofisticada apresentação da nação, a partir de seus recursos naturais. Ancorando-se, portanto, em uma perspectiva de progresso que era apresentada ao universo científico e viável como fornecedora de matérias primas importantes para a indústria. ${ }^{25}$ Sobre este aspecto, voltamos a mencionar o Catálogo Brasileiro da Exposição Universal de 1876, apresentado nas páginas anteriores, composto por quase seiscentas páginas de dados, mapas e tabelas. Ele revelava ao público das Exposições, e ao mundo em geral, um profundo conhecimento científico e tecnológico do que se pretendia apresentar.

A exibição dos recursos naturais pelo Brasil estava equiparada, nesse ponto, ao que era apresentado por outros países da América Latina, pela Austrália e mesmo pelo oeste dos Estados Unidos. Cribelli destaca que, para as nações e regiões mais jovens do globo, os estandes expostos internacionalmente assumiam outro significado, já que imprimiam, por meio de cuidadosa

${ }^{25}$ CRIBELLI, Teresa. "Forests at the Fair". Op. Cit, p.22. 
exposição de suas plantas, madeiras e recursos naturais variados, uma perspectiva de desenvolvimento que visava a atração de imigrantes e de capital. ${ }^{26}$ Essa premissa reforça a ideia defendida pela mesma autora: o que importava não era necessariamente a assimetria demonstrada entre os diversos expositores, mas a evidência efetiva da habilidade em consolidar informação científica e estatística dos recursos humanos, industriais e naturais das nações. ${ }^{27}$

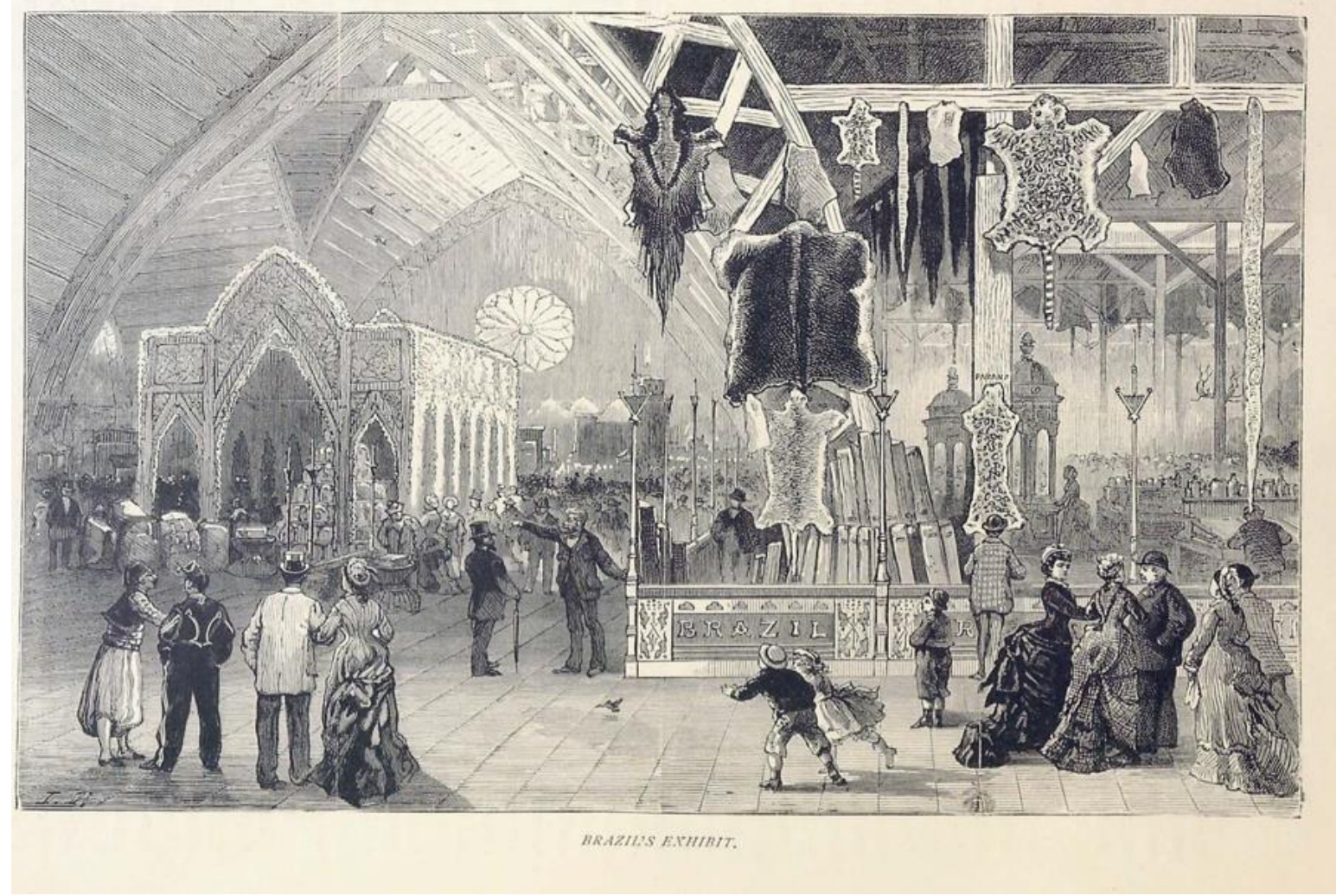

Figura1: Brazil's Exhibit, Historical Catalogue of the Centennial Exhibition, Philadelphia, 1876 (New York- John Filmer, 1876), p. $291^{28}$

A figura anterior, bastante elucidativa para o debate aqui alinhavado, nos apresenta o estande brasileiro na Exposição da Filadélfia: apresenta esse lugar que o Brasil decidiu ocupar a partir de suas próprias perspectivas. É possível perceber a variada tipologia de madeira exposta no seu interior, as peles de animais apropriadas como matéria prima para o desenvolvimento das indústrias. Cribelli pontua ainda um aspecto peculiar destes estandes, que se aproximavam em

${ }^{26}$ CRIBELLI, Teresa. "Forests att he Fair". Ibid, p. 6.

${ }^{27}$ CRIBELLI, Teresa. "Forests at the Fair" Op. Cit.

${ }^{28}$ Apud: CRIBELLI, Teresa. "O Império das Palmeiras, os Estados Unidos descobrem o Brasil, 1789-1892”, op. cit, p. 116. 
características como de outras nações ou regiões "periféricas": a arquitetura que remete a uma igreja, além da preocupação de todos eles com a exibição das suas riquezas naturais.

Seguindo essa trilha e a de outros estudos que vem apresentando esses interesses econômicos regionais na exibição nas Exposições, passamos à defesa de que a noção de modernidade em construção no Brasil na segunda metade dos oitocentos manteve estreito diálogo com os mais amplos interesses que se faziam presentes, visando a inserção do país nas redes internacionais de comércio. Os múltiplos debates sobre se o Brasil participaria das Exposições demonstram ao fim que a defesa do governo predominou, ainda que alicerçado nos interesses daqueles que aguardavam o retorno econômico potencialmente gerado pela exibição de tão rica quantidade, conhecimento e domínio de produtos brasileiros. Destacaram-se, como já mencionado, os catálogos que documentavam os avanços técnicos e científicos, como o conhecimento sobre a floresta e seus recursos naturais, que despertavam muito mais do uma mera atenção ou curiosidade, mas sim o interesse internacional sobre as potencialidades desta nação. Assim, podemos afirmar que todos os esforços estiveram sim concentrados em levar ao exterior um Brasil moderno, progressista e civilizado, ainda que agrário e imerso em ricas possibilidades de exploração natural. Sendo um exibidor privilegiado de tão diferentes tipos de matérias-primas que serviriam à ciência e à indústria, o Brasil estava longe de apresentar-se ao mundo em uma dimensão atrasada: os olhos se voltavam para a descoberta do potencial de exploração de seus recursos naturais em toda a sua dimensão.

\section{Em conclusão}

Acompanhadas ou não das modernas máquinas, as Exposições revelavam a vitória humana expressa no domínio da natureza. A natureza apresentada, nas palavras de Cribelli, estava organizada, catalogada, compreendida e exposta a uma utilidade comercial. Indicava, portanto, o claro e elevado nível de progresso alcançado por determinado governo, que ostentava o potencial para o futuro ao apontar a capacidade de reconhecer a utilidade dos recursos naturais. Os catálogos contendo descrições das plantas e especificidades de um amplo conhecimento sobre a madeira, por exemplo, revelam um rico patrimônio do país, bem como o incomensurável conhecimento botânico que se apresentava para além das redes científicas europeias, mostrando uma articulação entre o saber científico e o conhecimento indígena sobre tais recursos naturais. 
Pensando a regularidade da participação brasileira nas feiras internacionais e seu interesse e dedicação particular em realizar eventos internos de grande monta, redimensionamos o significado desses eventos para o Brasil. Para o governo e os setores proprietários com interesses diretos nas Exposições, elas representaram uma abertura do leque econômico: o café, o algodão e a madeira, as meninas dos olhos do Brasil no exterior, brilharam nas feiras internacionais como produtos privilegiados na pauta de exportação brasileira. Mas também outros surgiram novos aos olhos do mundo, encantando, surpreendendo e tornando-se nova seara para negócios. Além disso, o público que frequentava as exposições nacionais na Corte cresceu a olhos vistos ao longo da segunda metade do século XIX (a $2^{\mathrm{a}}$ exposição nacional, de 1866, chegou a receber 53.538 visitantes), ${ }^{29}$ mostrando a crescente popularização e fascínio que elas exerciam sobre a sociedade.

Nossa análise pretendeu trazer à tona também uma historiografia que vem apresentando novas questões a respeito da inserção do Brasil nas Exposições Universais, problematizando esse espaço de modernidade diante dos aspectos específicos que levavam o país a ter interesse em despender tantos recursos para participar delas. Esse outro olhar nos apresenta um país que mantinha a convivência com a escravidão e o pertencimento a uma rede internacional de comércio, onde buscava inserir-se mais contundentemente como um exportador de matérias primas variadas para as diversas regiões do mundo. Parte de um projeto imperial mais amplo, essa participação brasileira revelava a sua condição dentro das relações internacionais, onde sua riqueza natural tornava-se suas principais commodities.

${ }^{29}$ O Império do Brazil na Exposição Universal de 1862 em Paris. Biblioteca Nacional, III-17,5,15. 


\section{Bibliografia:}

BARBUY, Heloísa. “O Brasil vai a Paris em 1889: um lugar na Exposição Universal”. Anais do Museu Paulista. São Paulo, v.4, pp. 211-240, dez. 1996.

BARRETO, Rosendo Muniz. Exposição Nacional. Notas e observações. S/l, 1876, pp. 3-15.

CRIBELLI, Teresa. "Forests at the fair: Natural resources narratives of progress in the Brazilian and U. S. exhibits at the 1876 Philadelphia Exhibition". In: XXX International Congress of the Latin American Studies Association, San Francisco, maio 2012.

. “O Império das Palmeiras, os Estados Unidos descobrem o Brasil, 1789-1892”. In: MARTINS, Ana Cecilia Impellizieri \& SOCHACZEWSKI, Monique (Orgs.) As Descobertas do Brasil: o olhar estrangeiro na construção da imagem do Brasil. Rio de Janeiro: Casa da Palavra, 2014. pp.70-127.

"O mais útil de todos os instrumentos: o arado e a valorização da terra no Brasil no século XIX”. In: MOTTA, Márcia e SECRETO, Verônica (Orgs.). O Direito às avessas: por uma História Social da Propriedade. Guarapuava: Unicentro, 2011; Niterói: Eduff, 2011, pp. 291-312.

Aperfeiçoar or Criar: dilemmas of Brazilian modernization, 1850-1889. 2009. Tese (Doutorado em Filosofia), The Johns Hopkins University, Baltimore, Maryland.

FERREIRA, Cristina Araripe. Difusão do conhecimento científico e tecnológico no Brasil na segunda metade do século XIX: a circulação do progresso nas exposições universais e Internacionais. 2011. 138 f. Tese de Doutorado em História das Ciências e da Saúde, Fundação Oswaldo Cruz, Rio de Janeiro.HOBSBAWM, Eric. A Era do Capital. 1848-1875.9 a ed. Rio de Janeiro: Paz e Terra, 1996.

KUHLMANN Jr., Moysés. “As Exposições universais e a utopia do controle social”. XVII Simpósio Nacional de História. Anais do XVII Simpósio Nacional de História. São Paulo, julho 1993, pp.169-170.

MALAVOTA, L. M. A construção do sistema de patentes no Brasil: um olhar histórico. Rio de Janeiro: Editora Lumen Juris, 2011.

MARQUESE, Rafael. "Governo dos escravos e ordem nacional: Brasil e Estados Unidos, 18201860”, Penélope, n. 27, pp. 59-73, 2002.

MARTINS, M. "O impacto das Exposições Universais do século XIX para as relações econômicas brasileiras e o avanço tecnológico: uma análise sobre a participação das províncias". In: XII Congresso Brasileiro de História Econômica e $13^{\mathrm{a}}$ Conferência Internacional de História de empresas. Niterói, Universidade Federal Fluminense, 2017.

"A propriedade sobre o conhecimento: A participação do Brasil nas Exposições Universais do século XIX”. In: MOTTA, Márcia. O domínio de Outrem: as propriedades na História (Brasil e Portugal, séculos XVIII e XX). Guimarães; São Luís: Editora Nós por cá tudo bem; EDUEMA, 2017.

NABUCO, Joaquim. O Abolicionismo. São Paulo: Publifolha, 2000.

O Império do Brasil na Exposição Universal de 1876 na Philadelphia. Rio de Janeiro: Typographia Nacional, 1875.

PESAVENTO, Sandra Jatahy. Exposições universais: espetáculos da modernidade no século XIX. São Paulo: Editora Hucitec, 1997.

PLUM, Werner. Exposições no século XIX: espetáculos da transformação sócio-cultural. Bonn: Friedrich-Ebert-Stiftung, 1979.

SANJAD, Nelson; CASTRO, Ana Raquel de Marques. Comércio, política e Ciência nas Exposições Internacionais. O Brasil em Turim, 1911. Revista Varia Historia, Belo Horizonte, v. 31, n. 57, pp. 819-861, set/dez 2015. 
SCHWARCZ, Lilia Moritz. "Exposições Universais: festas do trabalho, festas do progresso. In: As barbas do imperador: D. Pedro II - um monarca nos trópicos. São Paulo: Cia das Letras, 1998, pp. 385-407.

SILVA, José Bonifácio de Andrada e "Representação à assembleia geral constituinte e legislativa do Império do Brasil sobre a escravatura" In: DOLHINIKOFF, Miriam. José Bonifácio de Andrada e Silva: Projetos para o Brasil. São Paulo: Companhia das Letras,1998.

Recebido em junho de 2017. Aceito em agosto de 2017. 